\title{
Claude Debon, "Calligrammes" dans tous ses états, édition critique du recueil de Guillaume Apollinaire
}

\section{Mario Richter}

\section{(2) OpenEdition}

1 Journals

\section{Edizione digitale}

URL: http://journals.openedition.org/studifrancesi/8047

DOI: 10.4000/studifrancesi.8047

ISSN: 2421-5856

\section{Editore}

Rosenberg \& Sellier

\section{Edizione cartacea}

Data di pubblicazione: 1 juillet 2009

Paginazione: 433-434

ISSN: 0039-2944

\section{Notizia bibliografica digitale}

Mario Richter, "Claude Debon, "Calligrammes" dans tous ses états, édition critique du recueil de Guillaume Apollinaire», Studi Francesi [Online], 158 (LIII | II) | 2009, online dal 30 novembre 2015, consultato il 13 janvier 2021. URL: http://journals.openedition.org/studifrancesi/8047 ; DOI: https://doi.org/10.4000/ studifrancesi.8047

Questo documento è stato generato automaticamente il 13 janvier 2021.

\section{(c) (1)}

Studi Francesi è distribuita con Licenza Creative Commons Attribuzione - Non commerciale - Non opere derivate 4.0 Internazionale. 


\title{
Claude Debon, "Calligrammes" dans tous ses états, édition critique du recueil de Guillaume Apollinaire
}

\author{
Mario Richter
}

\section{NOTIZIA}

CLAUDE DEBON, "Calligrammes" dans tous ses états, édition critique du recueil de Guillaume Apollinaire, Clamart, Éditions Calliopées, 2008, pp. 384.

1 Finora gli studiosi di Apollinaire disponevano di uno strumento prezioso per conoscere nella sua genesi la prima grande raccolta apollinairiana Alcools: s'intenda il ben noto Dossier d'“Alcools" pubblicato nel lontano 1960 da Michel Décaudin (rivisto dall'autore nel 1965 e riedito nel 1996). Dobbiamo ora a Claude Debon un'analoga impresa dedicata alla seconda grande raccolta del poeta, Calligrammes, impresa attuata con tutti i più utili mezzi della filologia, della critica storico-letteraria e della codicologia. Il lettore ha così modo di seguire passo passo, fin dai suoi minimi dettagli, la lenta, progressiva e costante formazione della raccolta, a partire dal progetto e realizzazione (con la collaborazione di alcuni amici pittori del poeta) di un libretto intitolato Et moi aussi je suis peintre e dal passaggio intermedio del raro fascicoletto Case d'armons fino all'allestimento definitivo dell'opera. È così possibile ripercorrere in modo particolarmente suggestivo la vita di Apollinaire nelle varie tappe che videro il poeta impegnato nell'attività bellica, dal 1914 al 1918 (che è anche l'anno della sua prematura morte). «La genèse des Calligrammes - afferma infatti l'A. - n'est pas séparable de l'histoire vécue par le poète-soldat» (p. 16). Grazie a questa edizione, delle venticinque copie di Case d'armons conosciamo ora la lista di buona parte dei destinatari, a cominciare dalla prima, inviata con dedica a Soffici. Con stile sobrio, concreto e piacevole l'A. ci dà tutte le informazioni necessarie per conoscere gli sforzi compiuti da Apollinaire per ricuperare da Lou e da Madeleine le poesie via via inviate alle due amiche: mentre Lou si rifiutò di restituirgli il consistente numero di versi che ricevette, 
Madeleine si rivelò molto più generosa e collaborativa, tanto che ventidue poesie che si leggono in Calligrammes le dobbiamo a lei. I capitoli successivi ci fanno seguire con precisione e chiarezza (grazie anche a tabulati) tutto ciò che è possibile sapere circa l'impegno profuso dal poeta ferito per arrivare a costituire e pubblicare la sua raccolta. La Debon non tralascia poi di informarci circa la ricezione dell'opera, fatta di elogi e incomprensioni. Di particolare interesse risulta il capitolo nel quale l'A., parlando dell' "originalité de Calligrammes», non vuole mai sovrapporsi a ciò che ci fa sapere lo stesso Apollinaire o i documenti dell'epoca. Un costante slancio verso l'avvenire e una vigile volontà di dar vita a una nuova realtà poetica caratterizzano la nuova raccolta, che alla fine si protende verso altri inattesi orizzonti. Da una lettera a Picasso dell'11 settembre 1918 sappiamo infatti che negli ultimi giorni di vita il poeta intendeva orientarsi verso una direzione, presumibilmente cristiana, confortata dalla visione di Pascal («Qu'y a-t-il encore aujourd'hui de plus neuf, de plus moderne, de plus dépouillé, de plus lourd de richesses que Pascal»). La bibliografia critica e la lista dei periodici completano molto utilmente l'ampia introduzione. Ciascuna poesia della raccolta è corredata dell'indicazione delle tappe della sua realizzazione (risultano così le varianti e quelli che l'A. chiama écarts), di una iconografia (riproduzione pressoché completa dei manoscritti rimasti), di preziose note, di un commento encomiabilmente essenziale e di una bibliografia specifica. Il volume si conclude con una bibliografia generale che sembra onorare il non facile criterio della completezza.

2 Ogni lettore e ogni studioso di Apollinaire deve salutare questa pubblicazione come un autentico avvenimento, come uno strumento ormai indispensabile per una conoscenza esatta e completa di una delle opere poetiche più importanti e feconde del Novecento. 